\title{
Unilateral Acute Renal Ischemia-Reperfusion Injury Induces Cardiac Dysfunction through Intracellular Calcium Mishandling
}

\author{
Carolina Victoria Cruz Junho ${ }^{1,2}$, , Laura González-Lafuente ${ }^{2}$, José Alberto Navarro-García ${ }^{2}$, \\ Elena Rodríguez-Sánchez ${ }^{2}\left(\mathbb{0}\right.$, Marcela Sorelli Carneiro-Ramos ${ }^{1, *} *$ and Gema Ruiz-Hurtado ${ }^{2,3, *}$ (B)
}

Citation: Junho, C.V.C.; GonzálezLafuente, L.; Navarro-García, J.A.; Rodríguez-Sánchez, E.; CarneiroRamos, M.S.; Ruiz-Hurtado, G Unilateral Acute Renal Ischemia-Reperfusion Injury Induces Cardiac Dysfunction through Intracellular Calcium Mishandling. Int. J. Mol. Sci. 2022, 23, 2266 https://doi.org/10.3390/ijms23042266

Academic Editors:

Anastasios Lymperopoulos

Received: 17 January 2022

Accepted: 14 February 2022

Published: 18 February 2022

Publisher's Note: MDPI stays neutral with regard to jurisdictional claims in published maps and institutional affiliations.

Copyright: (C) 2022 by the authors. Licensee MDPI, Basel, Switzerland. This article is an open access article distributed under the terms and conditions of the Creative Commons Attribution (CC BY) license (https:// creativecommons.org/licenses/by/ $4.0 /)$
1 Center of Natural and Human Sciences (CCNH), Federal University of ABC, Santo André 09210-580, SP, Brazil; carolina.junho@gmail.com

2 Cardiorenal Translational Laboratory, Institute of Research Imas12, Hospital Universitario 12 de Octubre, Community of Madrid, 28041 Madrid, Spain; laura.gonzlafuente@gmail.com (L.G.-L.); jalbertong@gmail.com (J.A.N.-G.); elena.rodsanchez@gmail.com (E.R.-S.)

3 CIBER-CV, Hospital Universitario 12 de Octubre, 28041 Madrid, Spain

* Correspondence: msorelli@gmail.com (M.S.C.-R.); gemaruiz@h12o.es (G.R.-H.); Tel.: +34-913908001 (G.R.-H.)

\begin{abstract}
Background: Acute renal failure (ARF) following renal ischemia-reperfusion (I/R) injury is considered a relevant risk factor for cardiac damage, but the underlying mechanisms, particularly those triggered at cardiomyocyte level, are unknown. Methods: We examined intracellular $\mathrm{Ca}^{2+}$ dynamics in adult ventricular cardiomyocytes isolated from C57BL/ 6 mice 7 or 15 days following unilateral renal I/R. Results: After 7 days of I/R, the cell contraction was significantly lower in cardiomyocytes compared to sham-treated mice. It was accompanied by a significant decrease in both systolic $\mathrm{Ca}^{2+}$ transients and sarco/endoplasmic reticulum $\mathrm{Ca}^{2+}$-ATPase $\left(\mathrm{SERCA}_{2 \mathrm{a}}\right.$ ) activity measured as $\mathrm{Ca}^{2+}$ transients decay. Moreover, the incidence of pro-arrhythmic events, measured as the number of $\mathrm{Ca}^{2+}$ sparks, waves or automatic $\mathrm{Ca}^{2+}$ transients, was greater in cardiomyocytes from mice 7 days after I/ $\mathrm{R}$ than from sham-treated mice. $\mathrm{Ca}^{2+}$ mishandling related to systolic $\mathrm{Ca}^{2+}$ transients and contraction were recovered to sham values 15 days after $I / R$, but $\mathrm{Ca}^{2+}$ sparks frequency and arrhythmic events remained elevated. Conclusions: Renal I/R injury causes a cardiomyocyte $\mathrm{Ca}^{2+}$ cycle dysfunction at medium (contraction-relaxation dysfunction) and long term (Ca ${ }^{2+}$ leak), after 7 and 15 days of renal reperfusion, respectively.
\end{abstract}

Keywords: renal ischemia and reperfusion; intracellular calcium handling; adult cardiomyocyte; cardiorenal syndrome; acute renal failure

\section{Introduction}

Acute renal failure (ARF) caused by renal ischemia-reperfusion (I/R) injury is a complex clinical entity related to a variety of clinical and surgical settings, including sepsis and kidney transplantation [1-3], and is characterized by the suspension of blood flow to the kidney followed by restoration of perfusion and re-oxygenation. While ARF is correlated with high morbidity and mortality [4], and with an incidence ranging from 5\% to up to $30 \%$ in patients treated in intensive care units [5], the renal failure per se is not commonly a primary cause of death, and it has been proposed that injury to extrarenal organs might explain the dismal outcome for patients [6]. Indeed, several studies have identified cardiac involvement as contributing to disease-related morbidity/mortality following I/R injury [7].

The complex physiological relationship that exists between the kidneys and the heart has long been appreciated, and damage to one organ may induce damage to the other, which has been termed the cardiorenal syndrome. This coexistence of cardiac and renal dysfunction has been classified into 5 types of cardiorenal syndrome based on the initial injured organ and the range of the conditions (acute or chronic) [8]. According to this 
classification scheme, acute cardiorenal syndrome type 3 is defined as cardiac injury secondary to ARF and is commonly observed after transplantation and use of nephrotoxic or cardiotoxic drugs [8].

Renal ischemia typically occurs in the setting of renal infarction, sepsis or kidney transplantation. It is often followed by an inflammatory state, redox imbalance and changes to the structure and function of renal cells, including apoptosis [9]. These features are also evident in cardiac tissue [10-13]. Previous studies from the group have already evidenced the importance of the first two weeks of renal reperfusion in the development of cardiac outcomes. After 7 days of renal I/R, we find a peak of systemic inflammation (maximum increase in inflammatory cytokines, TNF- $\alpha$, IFN- $\gamma$ and IL- $1 \beta$ ), electrophysiological changes in the heart (increased QT and QTc intervals) [10] and an increase in NOX and NOS activities, along with increased cardiac cell damage [13]. After 15 days of renal I/R, a concentric-type cardiac hypertrophy and electrical alterations were observed, given the increase of hypertrophy biomarkers such as B-type natriuretic peptide (BNP) and $\alpha$-actin $[10,14]$ together with the increase of the LV mass [10] and prolongation of the QJ interval [15]. Moreover, ARF progression to acute kidney disease triggers cardiac injury, including heart failure (HF) development, because of the volume overload, inflammatory activation and metabolic disturbances in uremia [16].

Heart function is tightly controlled by the intracellular $\mathrm{Ca}^{2+}$ handling that mediates membrane excitation and contraction (EC)-coupling during the cardiomyocyte contractionrelaxation. EC-coupling transforms electrical signals into mechanical force, which relies on tightly coordinated $\mathrm{Ca}^{2+}$ release and reuptake in cardiomyocytes [17]. Cardiac muscle contraction is initiated by the depolarization of the membrane of cardiomyocytes, activating transient $\mathrm{Ca}^{2+}$ entry through L-type $\mathrm{Ca}^{2+}$ channels from the extracellular medium. This small increase in cytosolic $\mathrm{Ca}^{2+}$ concentration triggers a pronounced release of $\mathrm{Ca}^{2+}$ from the sarcoplasmic reticulum (SR), given the opening of ryanodine receptors type 2 channels $\left(\mathrm{RyR}_{2}\right)$, in a physiological process termed $\mathrm{Ca}^{2+}$-induced $\mathrm{Ca}^{2+}$ release [15], inducing cardiomyocyte contraction. Relaxation occurs when cytosolic $\mathrm{Ca}^{2+}$ is transported back from the sarcoplasm to the SR. This process occurs principally by $\mathrm{Ca}^{2+}$-ATPase 2a pump $\left(\mathrm{SERCA}_{2 \mathrm{a}} \mathrm{Ca}^{2+}\right)$ re-uptake and also by $\mathrm{Ca}^{2+}$ extrusion to the extracellular medium by the $\mathrm{Na}^{+} / \mathrm{Ca}^{2+}$ exchanger [18]. Alterations in EC-coupling and $\mathrm{Ca}^{2+}$ handling are related to direct cardiac injury during HF by stimulating ventricular dysfunction and arrhythmia [18]. While defects in intracellular $\mathrm{Ca}^{2+}$ homeostasis are well known during $\mathrm{HF}$, playing a principal role in causing mechanical dysfunction and arrhythmia, little is known about the potential cardiac $\mathrm{Ca}^{2+}$ imbalance in ARF.

Deciphering the intracardiomyocyte alterations linked to $\mathrm{Ca}^{2+}$ handling would be clinically useful to better understand the extrarenal physiological consequences of ARF on the heart and may allow early intervention focused on protecting the myocardium in patients after I/R injury. Accordingly, the aim of the present study was to investigate whether ARF triggers relevant cardiac features related to cardiomyocyte dysfunction and intracellular $\mathrm{Ca}^{2+}$ handling in an experimental model of unilateral I/ $\mathrm{R}$ injury for 7 and 15 days.

\section{Results}

\subsection{Renal Ischemia and Reperfusion Induces Contractile Dysfunction}

We employed an experimental model of ARF to comprehensively analyze the cardiac consequences of acute unilateral renal I/ $R$ through the occlusion of the left renal pedicle. Macroscopic parameters of each experimental group are shown in Table 1. Left kidney weight/ body weight (LKW/BW) and left kidney weight/ tibia length (LKW/TL) ratios were significantly lower in $15 \mathrm{~d} \mathrm{I} / \mathrm{R}$ mice than in the other experimental groups $(p<0.001)$. In contrast to $\mathrm{LKW}$, the right kidney weight $(\mathrm{RKW}) / \mathrm{BW}$ ratio was significantly higher in the $7 \mathrm{~d} \mathrm{I} / \mathrm{R}$ and $15 \mathrm{~d}$ I/R groups than in the sham group ( $p<0.05$ and $p<0.01$, respectively), and RKW/TL was significantly increased in the $15 \mathrm{~d}$ I/R group $(p<0.05)$. These results indicate hypertrophy of the right kidney, likely because of compensational mechanisms to maintain 
renal function. In the same line, the $\mathrm{HW} / \mathrm{BW}$ and $\mathrm{HW} / \mathrm{TL}$ ratios were significantly higher in mice after $7(p<0.05)$ and $15(p<0.05$ and $p<0.01)$ days of renal I/R than in sham mice. We used both BW and TL in order to ensure that we normalized with respect to the growth of the animal (TL) and not only with BW. As the tibia is a non-variable measurement at short-term, the changes are more accurately quantified by relating heart/kidney weight to tibia length than to body weight after the I/R surgery.

Table 1. Macroscopic parameters in the ARF model 7 and 15 days following renal ischemia and reperfusion.

\begin{tabular}{|c|c|c|c|}
\hline Parameters & Sham & $7 \mathrm{~d} I / \mathrm{R}$ & $15 \mathrm{~d} \mathrm{I} / \mathrm{R}$ \\
\hline $\mathrm{BW}(\mathrm{g})$ & $24.0 \pm 0.5$ & $22.2 \pm 0.6$ & $23.2 \pm 0.7$ \\
\hline TL (mm) & $16.6 \pm 0.13$ & $16.2 \pm 0.12$ & $16.2 \pm 0.21$ \\
\hline HW (g) & $0.160 \pm 0.005$ & $0.177 \pm 0.009$ & $0.179 \pm 0.007$ \\
\hline LKW (g) & $0.151 \pm 0.004$ & $0.148 \pm 0.004$ & 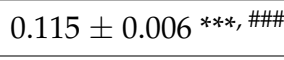 \\
\hline RKW (g) & $0.146 \pm 0.009$ & $0.167 \pm 0.005$ & $0.178 \pm 0.007$ * \\
\hline HW /BW (mg/g) & $6.7 \pm 0.21$ & $7.97 \pm 0.37 *$ & $7.77 \pm 0.32 * *$ \\
\hline $\mathrm{HW} / \mathrm{TL}(\mathrm{mg} / \mathrm{mm})$ & $96.9 \pm 3.09$ & $109.1 \pm 6.15^{*}$ & $110.2 \pm 3.34 *$ \\
\hline LKW /BW (mg/g) & $6.3 \pm 0.10$ & $6.7 \pm 0.28$ & $5.0 \pm 0.25^{* * *}$ \\
\hline $\mathrm{LKW} / \mathrm{TL}(\mathrm{mg} / \mathrm{mm})$ & $90.9 \pm 2.08$ & $91.1 \pm 2.83$ & 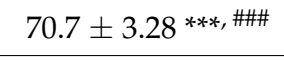 \\
\hline RKW /BW (mg/g) & $6.01 \pm 0.37$ & $7.56 \pm 0.36^{*}$ & $7.70 \pm 0.35^{* *}$ \\
\hline RKW/TL (mg/mm) & $88.3 \pm 5.63$ & $102.7 \pm 3.68$ & $109.2 \pm 3.85$ * \\
\hline
\end{tabular}

Morphometric data on kidney and heart weight and size in animals $(N=6-11) 7$ or 15 days following renal ischemia and reperfusion (7d I/R, 15d I/R). Data are expressed as mean \pm SEM. ${ }^{*} p<0.05,{ }^{* *} p<0.01$ versus sham; *** $p<0.001$ versus sham; \#\#\# $p<0.0017 \mathrm{~d}$ I/R. BW, body weight; TL, tibia length; HW, heart weight; LKW, left kidney weight; RKW, right kidney weight; I/R, ischemia and reperfusion.

We next examined renal damage by analyzing the plasma levels of urea, BUN, FGF-23 and phosphates (Table 2). Urea and BUN were significantly higher in the $7 \mathrm{~d}$ I/R group than in the sham group ( $p<0.05$, respectively). FGF-23 levels were significantly higher in the $15 \mathrm{~d}$ I/R group than in the sham group $(p<0.01)$, and FGF-23 levels were also significantly elevated when compared with levels in the $7 \mathrm{~d} I / \mathrm{R}$ group $(p<0.01)$. Likewise, phosphate levels were significantly higher in the $15 \mathrm{~d} I / \mathrm{R}$ group than in the $7 \mathrm{~d}$ I/R group $(p<0.05)$.

Table 2. Biochemical parameters in the ARF model 7 and 15 days following renal ischemia and reperfusion.

\begin{tabular}{cccc}
\hline Parameters & Sham & $\mathbf{7 ~ d ~ I / R}$ & $\mathbf{1 5 ~ d ~ I / R ~}$ \\
\hline Urea $(\mathrm{mg} / \mathrm{dL})$ & $40.9 \pm 2.5$ & $61.2 \pm 8.9^{*}$ & $51.6 \pm 3.2$ \\
\hline BUN & $19.1 \pm 1.2$ & $28.6 \pm 4.2^{*}$ & $24.1 \pm 1.5$ \\
\hline FGF-23 (pg/mL) & $186.6 \pm 50.5$ & $298.0 \pm 65.2$ & $759.7 \pm 151.1^{* *}$,\# \\
\hline Phosphate $(\mathrm{mg} / \mathrm{dL})$ & $6.05 \pm 1.01$ & $4.43 \pm 1.01$ & $9.33 \pm 1.74^{\#}$ \\
\hline
\end{tabular}

Plasma levels of kidney function (urea, BUN and phosphate) and (FGF-23) in animals ( $N=6-11) 7$ or 15 days following renal ischemia and reperfusion $\left(7 \mathrm{~d} I / \mathrm{R}, 15 \mathrm{~d}\right.$ I/R). Data are expressed as mean \pm SEM. ${ }^{*} p<0.05$ ** $p<0.01$ versus sham; \# $p<0.05$, \#\# $p<0.01$ versus $7 \mathrm{~d}$ I/R. BUN, blood urea nitrogen; FGF-23, fibroblast growth factor-23; I/R, ischemia and reperfusion.

Subsequently, we investigated whether renal I/R could trigger changes to cardiomyocyte contractility using Fluo 3-AM loaded isolated adult ventricular cardiomyocytes. Representative cell-shortening profiles of cardiomyocytes from the three experimental groups are shown in Figure 1A. Cardiomyocyte contraction was significantly lower in the $7 \mathrm{~d}$ I/R group than in the sham group $(p<0.001$; Figure 1B), and this was accompanied 
by significantly slower shortening and lengthening velocities ( $p<0.001$; Figure $1 C, D)$. Notably, cell contraction and both shortening and lengthening velocities were recovered 15 days after renal I/R (Figure 1A), and all parameters were both significantly higher than those observed in cells from $7 \mathrm{~d}$ I/R mice $(p<0.001)$ and were closer to those observed in cardiomyocytes from sham mice (Figure 1B-D). Similar results have been previously observed in cardiac function in this experimental model of cardiorenal damage, in which $15 \mathrm{~d}$ I/R did not change echocardiographic parameters as shortening fraction, ejection fraction or cardiac output [10].

A

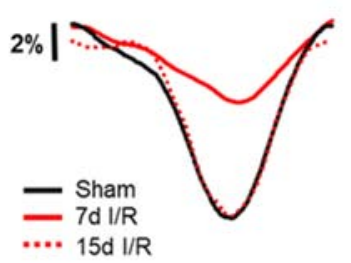

C

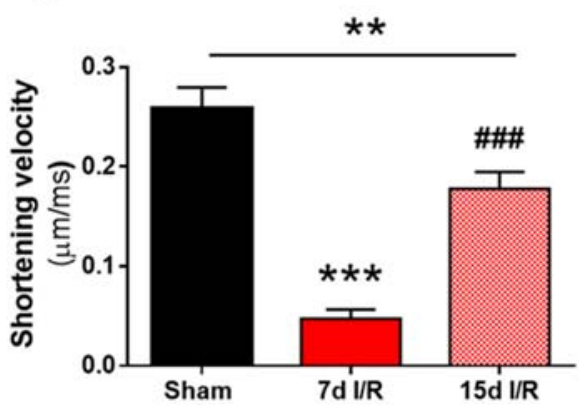

B

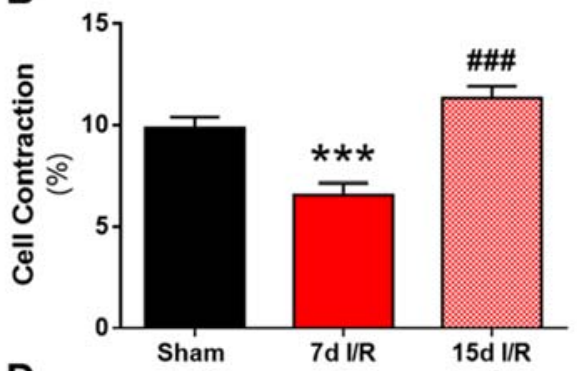

D

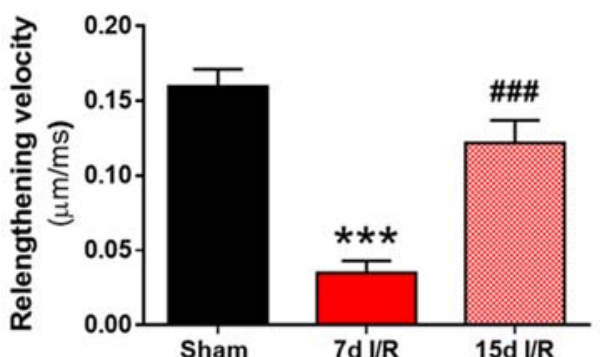

Figure 1. Contractility of electrically-stimulated cardiomyocytes after renal ischemia and reperfusion. (A) Cell contraction profiles of cardiomyocytes from sham-treated mice (black line) and from mice subjected to ischemia and reperfusion (I/R) for 7 (red line) and 15 (red discontinuous line) days. (B-D) Cell contraction (B), shortening (C) and re-lengthening (D) velocities. Cardiomyocytes were electrically stimulated at $2 \mathrm{~Hz}$. Data are expressed as mean \pm SEM. ${ }^{* *} p<0.01,{ }^{* * *} p<0.001$ versus sham, ${ }^{\# \#} p<0.001$ versus $7 \mathrm{~d} \mathrm{I} / \mathrm{R}$; sham $(n=73$ cells, $N=10$ mice), $7 \mathrm{~d} \mathrm{I} / \mathrm{R}$ ( $n=39$ cells, $N=10$ mice) and $15 \mathrm{~d} \mathrm{I} / \mathrm{R}$ ( $n=90$ cells, $N=6$ mice).

\subsection{Systolic $\mathrm{Ca}^{2+}$ Release Deteriorates 7 Days following Renal Ischemia and Reperfusion}

Given the strong link between cardiac contractile dysfunction and alterations in intracellular $\mathrm{Ca}^{2+}$ handling and the release of $\mathrm{Ca}^{2+}$ from the SR, we next analyzed systolic $\mathrm{Ca}^{2+}$ release by measuring $\mathrm{Ca}^{2+}$ transients. Representative line-scan $\mathrm{Ca}^{2+}$ images obtained from Fluo-3AM-loaded cardiomyocytes during electrical stimulation at $2 \mathrm{~Hz}$ are shown in Figure $2 \mathrm{~A}$, and correspond to the sham (left panel), $7 \mathrm{~d}$ (medium panel) or $15 \mathrm{~d}$ (right panel) renal I/R groups. Analysis revealed that the amplitude of the intracellular $\mathrm{Ca}^{2+}$ transients (measured as the peak $\mathrm{F} / \mathrm{F}_{0}$ ) was significantly lower in cardiomyocytes from the $7 \mathrm{~d} \mathrm{I} / \mathrm{R}$ mice than from the equivalent sham mice $(p<0.001$; Figure $2 \mathrm{~B})$, and the decline recovered significantly after 15 days of renal injury $(p<0.001$; Figure $2 \mathrm{~B})$. The time constant of $\mathrm{Ca}^{2+}$ transients decay (Tau) in cardiomyocytes was significantly longer in the $7 \mathrm{~d} \mathrm{I} / \mathrm{R}$ group than in the sham group ( $p<0.001$; Figure 2C), indicating a slower decay, but recovered 15 days after renal I/ R $\left(p<0.001\right.$; Figure 2C). These effects on $\mathrm{Ca}^{2+}$ kinetics indicate a decline in the systolic $\mathrm{Ca}^{2+}$ peak, with prolongation of the duration of systolic $\mathrm{Ca}^{2+}$ transients and compromised re-pumping of $\mathrm{Ca}^{2+}$ back into the SR in mice after $7 \mathrm{~d}$ of renal I/R. SERCA $2 \mathrm{a}$ expression were significantly decreased after renal I/R (Figure 2D,E). 
A

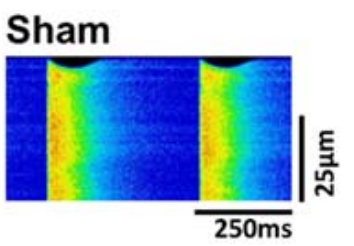

B

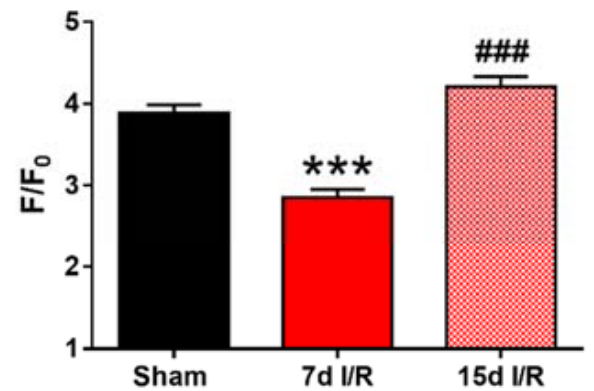

D

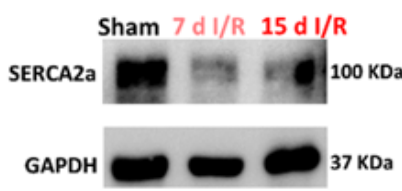

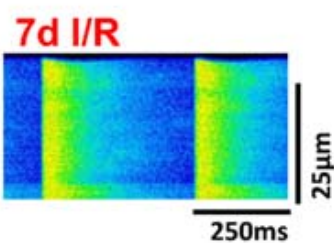

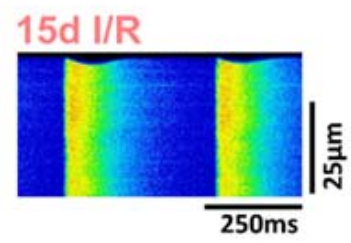

C

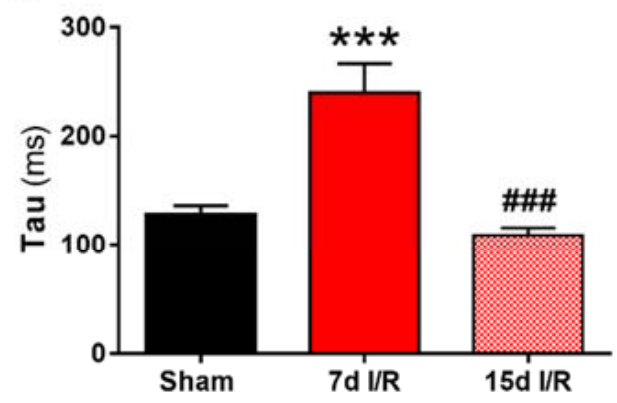

E

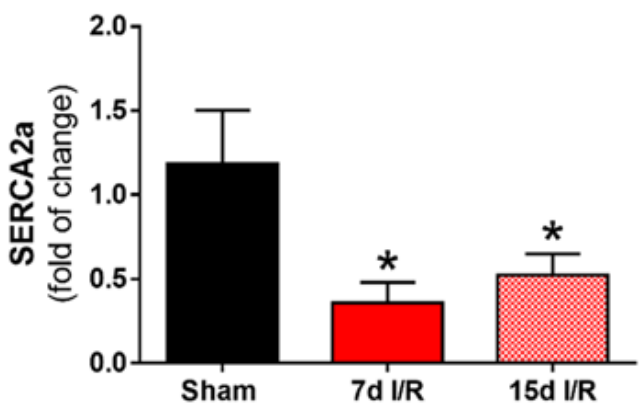

Figure 2. Systolic $\mathrm{Ca}^{2+}$ transient release in electrically stimulated cardiomyocytes. (A) Representative line-scan images of cardiomyocytes from sham-treated mice and from mice subjected to ischemia and reperfusion (I/R) for 7 and 15 days. Cardiomyocytes were electrically stimulated at $2 \mathrm{~Hz}$. (B) Mean peak fluorescence $\mathrm{Ca}^{2+}$ transients $\left(\mathrm{F} / \mathrm{F}_{0}\right)$. (C) Decay time constant, Tau (ms). Data are expressed as mean \pm SEM. ${ }^{* * *} p<0.001$ versus sham, ${ }^{\# \# \# ~} p<0.001$ versus $7 \mathrm{~d} \mathrm{I} / \mathrm{R}$; sham $(n=80$ cells, $N=10$ mice), $7 \mathrm{~d}$ I/R ( $n=61$ cells, $N=10$ mice), and $15 \mathrm{~d}$ I/R ( $n=91$ cells, $N=6$ mice). (D) Representative immunoblots of SERCA ${ }_{2 a}$ and GAPDH and (E) quantification of all experiments corresponding to cardiac protein expression. Data are presented as fold of change of sham levels \pm SEM (sham $=9$; $7 \mathrm{~d} \mathrm{I} / \mathrm{R}=8 ; 15 \mathrm{~d} \mathrm{I} / \mathrm{R}=8) .{ }^{*} p<0.05$ versus sham.

We next questioned whether the changes in systolic $\mathrm{Ca}^{2+}$ release are related to alterations in SR $\mathrm{Ca}^{2+}$ load. Applying caffeine to isolated Fluo-3-loaded cardiomyocytes, $\mathrm{Ca}^{2+}$ stores from the SR were depleted. Representative line-scan images of caffeine-evoked $\mathrm{Ca}^{2+}$ transients are shown in Figure 3 and correspond to the sham (upper panel), $7 \mathrm{~d}$ (medium panel) or $15 \mathrm{~d}$ (bottom panel) I/R groups. Results showed that the amplitude of caffeine-evoked $\mathrm{Ca}^{2+}$ transients in cardiomyocytes was significantly lower in the $7 \mathrm{~d} \mathrm{I} / \mathrm{R}$ group than in the sham group $(p<0.05$; Figure $3 \mathrm{~B})$, and that it was re-established in the $15 \mathrm{~d}$ I/R group ( $p<0.05$; Figure 3B). This occurred without significant changes in the rate of the decay time constant, Tau, in caffeine-exposed cardiomyocytes in any experimental group (Figure 3C). 
A

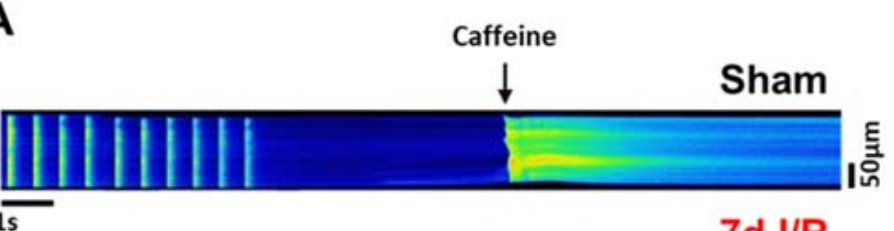

is

$7 d \mathrm{I} / \mathrm{R}$

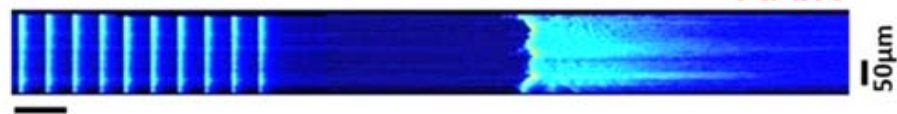

1s

B
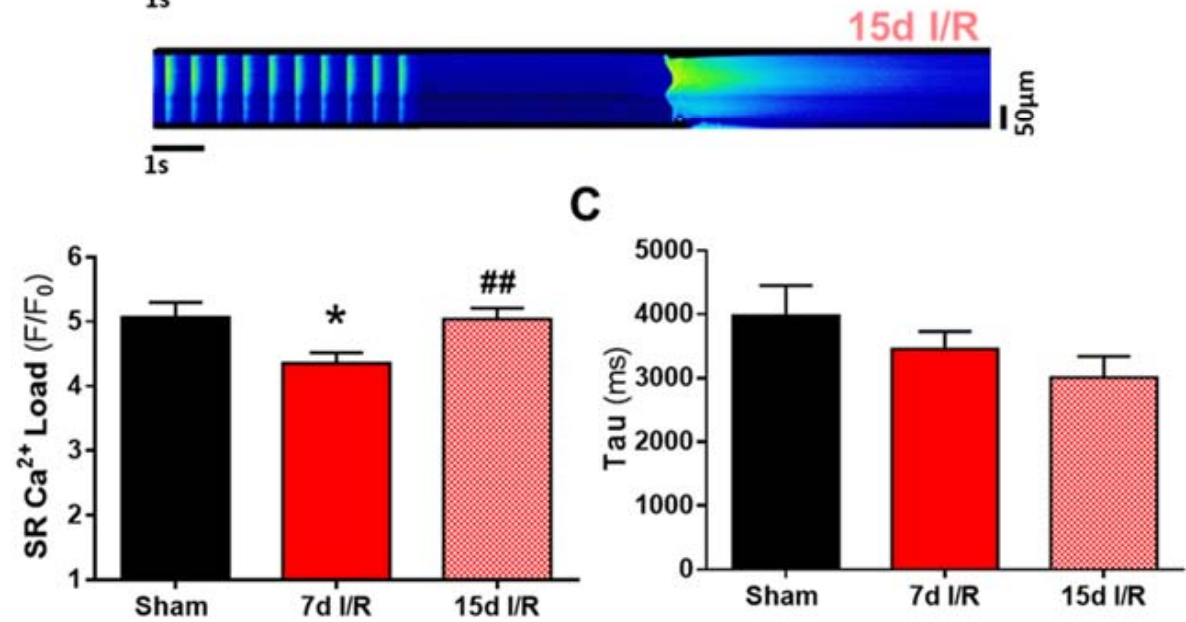

Figure 3. Sarcoplasmic reticulum $\mathrm{Ca}^{2+}$ load analysis on electrically stimulated cardiomyocytes. (A) Representative line-scan images of caffeine-evoked $\mathrm{Ca}^{2+}$ transients in cardiomyocytes from sham-treated mice and from mice subjected to ischemia and reperfusion (I/R) for 7 and 15 days. Cardiomyocytes were electrically stimulated at $2 \mathrm{~Hz}$. (B) Mean values of the transient amplitude evoked by caffeine (peak fluorescence calcium, $\mathrm{F} / \mathrm{F}_{0}$ ) in stimulated cardiomyocytes. $(\mathrm{C})$ Decay time constant, Tau, in milliseconds. Data are expressed as mean \pm SEM. ${ }^{*} p<0.05$ versus sham, ${ }^{\# \#} p<0.01$ versus $7 \mathrm{~d} \mathrm{I} / \mathrm{R}$; sham ( $n=37$ cells, $N=10$ mice), $7 \mathrm{~d} \mathrm{I} / \mathrm{R}(n=59$ cells, $N=10$ mice), and $15 \mathrm{~d} \mathrm{I} / \mathrm{R}$ ( $n=73$ cells, $N=6$ mice).

\subsection{Acute Renal Failure Induces Diastolic $\mathrm{Ca}^{2+}$ Release from the Sarcoplasmic Reticulum and Triggers Pro-Arrhythmic Ca ${ }^{2+}$ Events 7 Days of Renal Ischemia and Reperfusion That Remain} Elevated after 15 Days

As alterations in SR $\mathrm{Ca}^{2+}$ load are frequently associated with changes in diastolic $\mathrm{Ca}^{2+}$ release, we next analyzed the frequency and the kinetic property of spontaneous $\mathrm{Ca}^{2+}$ sparks. Representative line-scan images of no stimulated cardiomyocytes are shown in Figure $4 \mathrm{~A}$ and correspond to the sham (upper panel), $7 \mathrm{~d}$ (medium panel) and $15 \mathrm{~d}$ (bottom panel) I/R groups. Results showed that the frequency of $\mathrm{Ca}^{2+}$ sparks was significantly higher in cardiomyocytes at 7 and 15 days after ARF (Figure 4B; $p<0.001$ ) than in cells from sham mice. Analysis of the morphological properties of $\mathrm{Ca}^{2+}$ sparks showed that the amplitude (peak $\mathrm{F} / \mathrm{F}_{0}$ ) and full width was significantly lower in cardiomyocytes from $7 \mathrm{~d}$ I/R mice than from sham mice (Figure $4 \mathrm{C}, \mathrm{D} ; p<0.001, p<0.05$, respectively). Both parameters recovered 15 days after renal I/ $\mathrm{R}$ and were similar to those of sham cardiomyocytes (Figure 4C,D; $p<0.001, p<0.05$, respectively vs. $7 \mathrm{~d}$ I/R). No differences were found in the duration of $\mathrm{Ca}^{2+}$ sparks between the three experimental groups (Figure $4 \mathrm{E}$ ). 
A

\section{Sham}

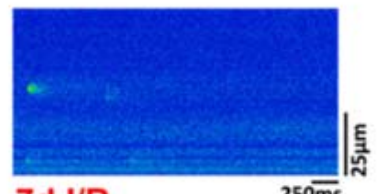

B

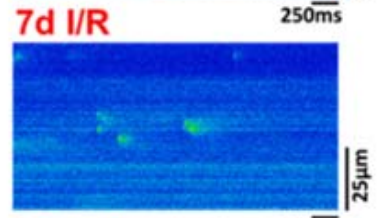

$15 d \mathrm{~d} / \mathrm{R}$

$250 \overline{\mathrm{ms}}$
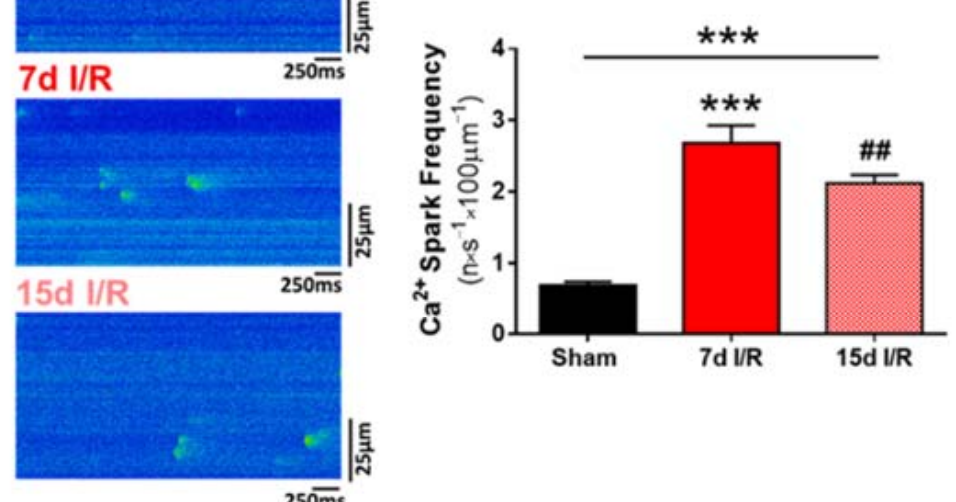

C

D
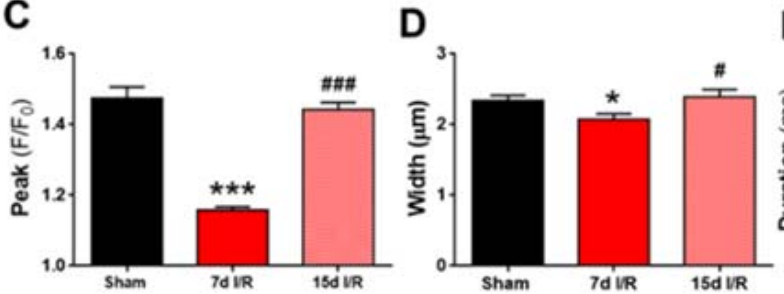

E

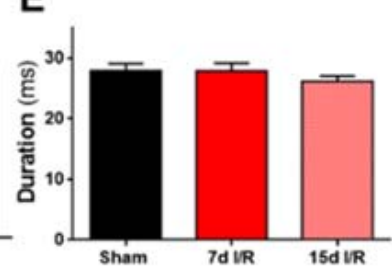

Figure 4. Diastolic $\mathrm{Ca}^{2+}$ leak in cardiomyocytes after renal I/R. (A) Representative line-scan images of $\mathrm{Ca}^{2+}$ sparks in quiescent cardiomyocytes from sham-treated mice and from mice subjected to ischemia and reperfusion (IR) for 7 and 15 days. (B) Frequency of $\mathrm{Ca}^{2+}$ sparks (presented in $n \cdot \mathrm{s}^{-1} \cdot 100 \mu \mathrm{m}^{-1}$ ). (C) Mean peak of fluorescence $\mathrm{Ca}^{2+}$ sparks $\left(\mathrm{F} / \mathrm{F}_{0}\right)$. (D) Full width at half maximum of fluorescence of sparks $(\mu \mathrm{m})$. (E) Full duration at half maximum of fluorescence $\mathrm{Ca}^{2+}$ sparks (ms). Data are expressed as mean \pm SEM. ${ }^{*} p<0.05,{ }^{* * *} p<0.001$ versus sham; ${ }^{\#} p<0.05,{ }^{\# \#} p<0.01$ versus and \#\#\# $p<0.001$ versus $7 \mathrm{~d} \mathrm{I} / \mathrm{R}$. sham ( $n=57$ cells, $\mathrm{N}=10$ mice), $7 \mathrm{~d} \mathrm{I} / \mathrm{R}(n=43$ cells, $N=10$ mice) and $15 \mathrm{~d}$ I/R ( $n=85$ cells, $N=6$ mice).

We next analyzed spontaneous $\mathrm{Ca}^{2+}$ waves and automatic $\mathrm{Ca}^{2+}$ transients during diastole, which were quantified as spontaneous $\mathrm{Ca}^{2+}$ release (SCR) in quiescent cardiomyocytes. Two representative examples of $\mathrm{Ca}^{2+}$ waves are shown in Figure 5A and correspond to cardiomyocytes isolated 7 (upper panel) and 15 (bottom panel) days after I/R. Quantification of the spontaneous $\mathrm{Ca}^{2+}$ events revealed that the occurrence of SCR was significantly higher after ARF, both at 7 (Figure 5B; $p<0.01$ ) and 15 (Figure 5B; $p<0.001$ ) days. There is a direct association between altered intracellular $\mathrm{Ca}^{2+}$ handling and a predisposition to fatal ventricular arrhythmias.

Accordingly, we next evaluated the presence of pro-arrhythmic behavior as spontaneous $\mathrm{Ca}^{2+}$ waves or transients evoking extra-contraction and missing $\mathrm{Ca}^{2+}$ transients in ventricular cardiomyocytes stimulated at $2 \mathrm{~Hz}$ for three cycles, each separated with a non-pacing period. Representative line-scan images of a normal cellular response corresponding to a cardiomyocyte from a sham-treated mouse is shown in Figure 6A (upper panel), and cardiomyocytes from mice after 7 and 15 days are shown in the middle and lower panels, respectively. Results showed that automatic $\mathrm{Ca}^{2+}$ dependent pro-arrhythmic events were significantly greater in cardiomyocytes from the renal I/R group (more than $30 \%$ of cells showed events) than cardiomyocytes from sham mice, both at 7 and 15 days following renal I/R (Figure 6B; $p<0.001$ ). 


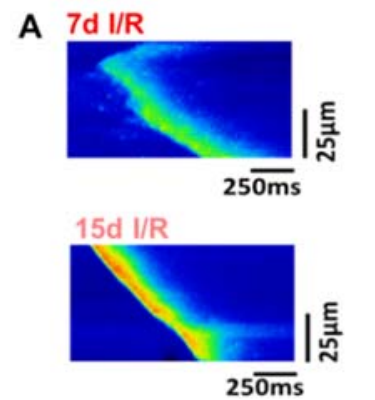

B

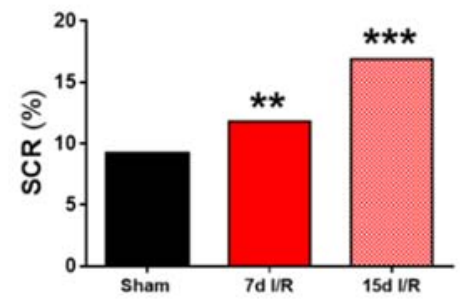

Figure 5. Spontaneous $\mathrm{Ca}^{2+}$ release in cardiomyocytes after renal I/R. (A) Representative line-scan images of cardiomyocytes from mice subjected to ischemia and reperfusion (I/R) for 7 and 15 days. (B) Spontaneous $\mathrm{Ca}^{2+}$ release measured as pro-arrhythmogenic events in cardiomyocytes. Data are presented as \% of total analyzed cells. Data are expressed as mean of continuous variables after Fisher test. ${ }^{* *} p<0.01,{ }^{* * *} p<0.001$ versus sham; sham ( $n=56$ cells, $N=4$ mice), $7 \mathrm{~d}$ I/R $(n=50$ cells, $N=3$ mice), $15 \mathrm{~d}$ I/R ( $n=99$ cells, $N=6$ mice). In this protocol each cell was recorded 8 consecutive times for $1.5 \mathrm{~s}$. Statistical analyses were performed per scanned-file.

A
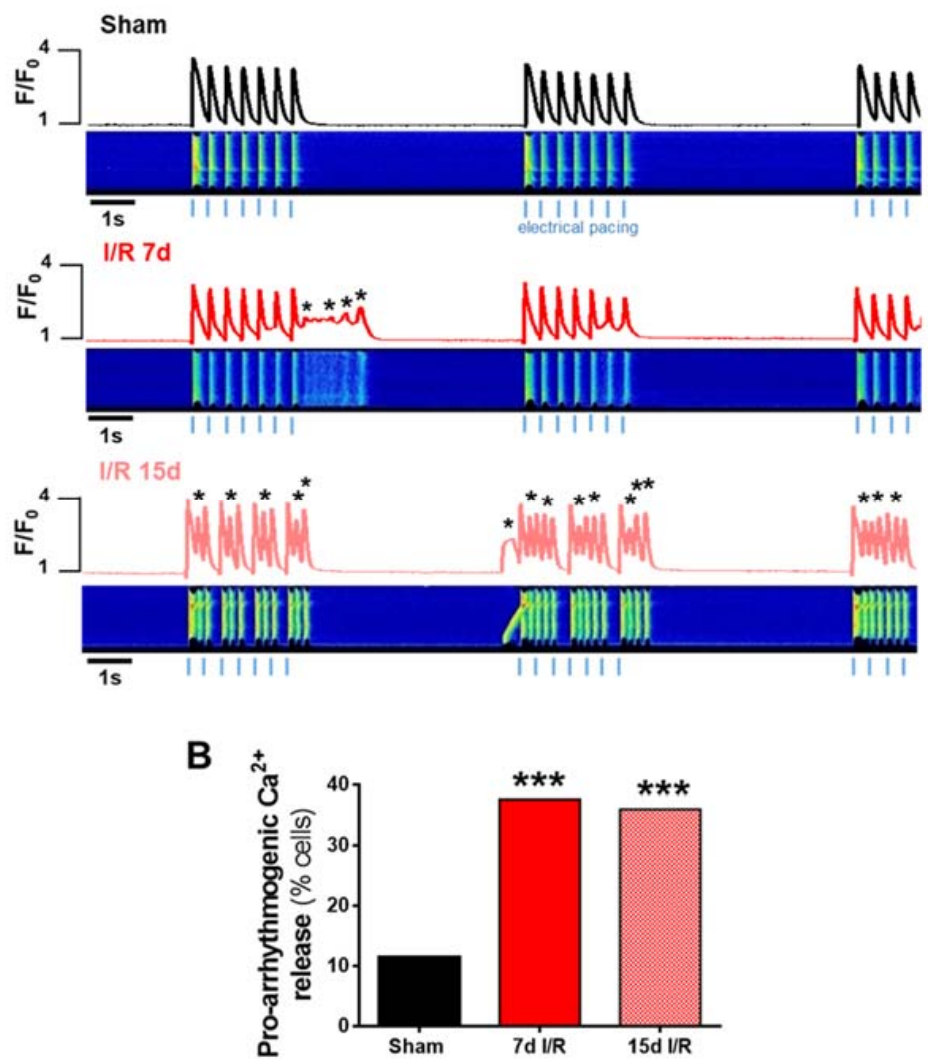

Figure 6. Pro-arrhythmogenic events in electrically stimulated cardiomyocytes. (A) Representative line-scan images and contraction profiles of cardiomyocytes from sham-treated mice and from mice subjected to ischemia and reperfusion (IR) for 7 and 15 days. Cardiomyocytes were electrically stimulated at $2 \mathrm{~Hz}$ in 7-pulse sequences. * Represents arrhythmic $\mathrm{Ca}^{2+}$ events (spontaneous abnormal release of $\mathrm{Ca}^{2+}$ as waves or automatic contractions). (B) Proarrhythmogenic $\mathrm{Ca}^{2+}$ release following the arrhythmia protocol in cardiomyocytes. Data presented as \% of total analyzed cells with events. Data are expressed as mean of continuous variables after Fisher test. ${ }^{* * *} p<0.001$ versus sham; sham ( $n=113$ cells, $N=5$ mice), $7 \mathrm{~d} \mathrm{I} / \mathrm{R}(n=77$ cells, $N=7$ mice), 15d I/ $\mathrm{R}(n=150$ cells, $N=6$ mice). In this protocol, each cell was recorded once for $30 \mathrm{~s}$. Statistical analyses were performed per cell. 


\section{Discussion}

In the present study, we show that ARF induces intracellular $\mathrm{Ca}^{2+}$ mishandling, manifested as cardiomyocyte contractile dysfunction 7 days after left unilateral renal occlusion, which recovers 15 days after the renal I/R. Likewise, ARF increases the incidence of cardiomyocyte pro-arrhythmic $\mathrm{Ca}^{2+}$ events in the heart after 7 and 15 days in vitro, indicating that aberrant diastolic $\mathrm{Ca}^{2+}$ leak, and thus the risk of arrhythmic events, continues in the long term. The findings of this study are corroborated by other studies from our group that demonstrated the efficiency of renal I/R to promote arrhythmogenic events in vivo using the isoproterenol challenge after 15 days of reperfusion [15].

ARF is associated with an unacceptably high rate of mortality despite being recognized for more than 40 years [4]. ARF is considered a risk factor for the generation of cardiac disease, while HF is one of the most typical causes of death in patients with ARF $[7,16]$. As yet, the pathophysiological mechanisms of cardiac failure in ARF remain unresolved and identifying these mechanisms will be an important first step in reducing the high cardiovascular morbidity and mortality related to ARF. In this sense, the intracellular mechanisms governing $\mathrm{Ca}^{2+}$ handling are an important platform to investigate cardiomyocyte contractility. Even though they are very often described in other cardiac diseases, such as $\mathrm{HF}$, the mechanisms surrounding $\mathrm{Ca}^{2+}$ handling dysfunction have not yet been studied much in the context of acute cardiorenal syndrome type 3 .

The present study shows-for the first time, to the best of our knowledge-relevant dysfunctional $\mathrm{Ca}^{2+}$ handling in ventricular cardiomyocytes in an experimental model of ARF at early ( 7 days) and later ( 15 days) stages following renal I/R injury. Our results establish an early impairment in cardiomyocyte contraction-relaxation processes after 7 days of renal I/ $\mathrm{R}$ that is chiefly due to: (1) a decrease in systolic $\mathrm{Ca}^{2+}$ release, observed as a reduction in $\mathrm{Ca}^{2+}$ transient amplitude; (2) an increase in the decay time constant of $\mathrm{Ca}^{2+}$ transients; and (3) a depressed SR Ca ${ }^{2+}$ load. The $\mathrm{Ca}^{2+}$ handling abnormalities, together with the compromised contraction-relaxation cycle in cardiomyocytes observed 7 days post-renal I/R, are similar to what is observed in several models of HF [19-21]. Our data indicate that $\mathrm{Ca}^{2+}$ reuptake into the SR is impaired in ventricular cardiomyocytes after 7 days of renal I/R, which is considered an early phase of kidney injury. This could be explained by the reduction in expression or activity of SERCA $A_{2 a}$. Similar to that which occurs in HF [21], the decline in SERCA ${ }_{2 a}$ function might explain the depletion of $\mathrm{Ca}^{2+}$ stores in the SR, the lower transient amplitudes and the impaired cellular contractility. These activities recovered 15 days after renal I/ $R$ in mice and were similar to cardiomyocytes from sham mice. A plausible explanation for this recovery is that ARF after 15 days is considered a transition period between the acute and chronic state of post-renal injury, according to the guidelines of the Kidney Disease: Improving Global Outcomes (KDIGO) organization [22], and it is possible that the initial cardiac damage at this time, at least in terms of contractile-relaxation, is compensated for. Indeed, the heart outcomes concerning the $\mathrm{Ca}^{2+}$ mishandling in systole seem to be set before the 7th day. Analyzing the adult cardiomyocytes in previous timepoints could provide us a superior understand about the acuteness of the cardiac dysfunction after renal I/R.

An increase in SR Ca ${ }^{2+}$ leak during diastole is a known and shared $\mathrm{Ca}^{2+}$-dependent pathological mechanism associated with the HF progression and arrhythmias $[17,23]$. The $\mathrm{Ca}^{2+}$ leak is a phenomenon defined as an inappropriate release of $\mathrm{Ca}^{2+}$ from the SR [24]. In pathological conditions with direct damage of the heart as in HF or indirect as in ARF observed in the present study, there is a high release of $\mathrm{Ca}^{2+}$ from SR during diastole (manifested as a higher frequency of $\mathrm{Ca}^{2+}$ sparks, waves and spontaneous $\mathrm{Ca}^{2+}$ transients). This increased release of $\mathrm{Ca}^{2+}$ leak reduces its availability for the subsequent contraction, thereby impairing contractility as it was observed after 7 days of renal I/R. However, despite the evident cardiac improvement in terms of systolic $\mathrm{Ca}^{2+}$ handling and contraction after 15 days of renal I/R, diastolic $\mathrm{Ca}^{2+}$ leak remains abnormally elevated.

The increase in diastolic $\mathrm{Ca}^{2+}$ leak is potentially a pathological substrate for the induction of arrhythmias, as the released $\mathrm{Ca}^{2+}$ from the SR can diffuse to neighboring $\mathrm{RyR}_{2}$ 
clusters to induce pro-arrhythmogenic $\mathrm{Ca}^{2+}$ events that, together with automatic contractions, ultimately trigger ventricular arrhythmias. Gambardella et al. reinforced that the $R Y R_{2}$ represents the central target of many pathways dysregulated in cardiac pathological conditions, including metabolic disorders, ROS production and inflammation [24]. All these alterations are accompanied by alterations in $\mathrm{Ca}^{2+}$ handling and subsequent impairment in cardiac contraction. The study of stabilization of $R Y R_{2}$ seems to be the main target for clinical practice, being studied in models of genetic mutation in human stem cells derived cardiomyocytes [25] and as a target in HF [26]. Evidently, analyzing the RYR 2 protein expression would be enlightening to provide a better understanding for the cardiorenal syndrome type 3 and its consequences to the heart.

A possible explanation for these results is that renal injury was sustained or worsened after 15 days of $\mathrm{I} / \mathrm{R}$, which is supported by the finding that the highest levels of FGF-23 were observed 15 days after renal I/R. FGF-23 is one of the most important components of mineral and bone metabolism and its excess is linked to the progression of renal dysfunction [27]. FGF-23 is a bone-produced hormone involved mainly in the response to an increase in parathyroid hormones, vitamin $\mathrm{D}$ or phosphorus. In the kidney, it binds to the FGF receptor and to its membrane co-receptor Klotho, to stimulate phosphaturia. Systemic FGF-23 levels rapidly increase as renal function declines, and this occurs before an increase in other markers, such as parathyroid hormone, vitamin D or even phosphorus, likely as a compensatory mechanism to prevent hyperphosphatemia after ARF [28,29]. In recent years, FGF-23 has also been established as an independent modulator of the heart [30-32]. Functionally, it has been demonstrated that FGF-23 triggers pro-arrhythmogenic cellular events in the HL-1 murine atrial cardiomyocyte cell line [33]. This might go some way to explain the clinical data showing that higher systemic FGF-23 levels are associated with a higher incidence of atrial fibrillation [34]. Moreover, it has recently been demonstrated that FGF-23 can induce relevant changes in $\mathrm{Ca}^{2+}$ handling in adult ventricular cardiomyocytes [31,35]. Analogous to our findings in ventricular cardiomyocytes from mice with renal $I / R$, the exposure to FGF-23 induced spontaneous diastolic spontaneous $\mathrm{Ca}^{2+}$ leak from the SR in the form of $\mathrm{Ca}^{2+} \mathrm{SCR}$ and triggered in vitro pro-arrhythmogenic activity as automatic systolic $\mathrm{Ca}^{2+}$ transients and extra-contractions. Therefore, our results suggest that the vulnerability to ventricular arrhythmias at early and longer term after I/R injury might be explained, at least in part, by the elevated and maintained circulating FGF-23 levels.

In conclusion, our study reveals a different pattern of cardiac damage at the medium and long terms after ARF, characterized by $\mathrm{Ca}^{2+}$ cycle dysfunction in ventricular cardiomyocytes. Despite the resolution of the initial contraction-relaxation dysfunction, the $\mathrm{Ca}^{2+}$ leak observed during diastole remains as an important sequela (Figure 7) that might have a significant impact on long-term cardiac outcomes such as fatal ventricular arrhythmias in patients with ARF. In fact, 7 and 15 days are important timepoints to observe the most important alterations in this ARF model, however, assess the $\mathrm{Ca}^{2+}$ behavior in other different timepoints was a limitation of the study. Evaluate cardiomyocytes of animals of previous and future reperfusion times would clarify the understand about the acuteness dysfunction observed after 7 days of renal I/R, as well as the consequence of maintained $\mathrm{Ca}^{2+}$ leak after 15 days, respectively.

Overall, our study provides a framework to better understand the mechanisms related to cardiac alterations and the elevated risk of major cardiovascular events including cardiac dysfunction and or fatal arrhythmias and cardiovascular mortality observed in patients with ARF. It may also serve as a basis for future pharmacological therapies focused on preventing the deleterious effects of mineral bone components in the uremic context and better managing fatal cardiac outcomes in patients with ARF. 


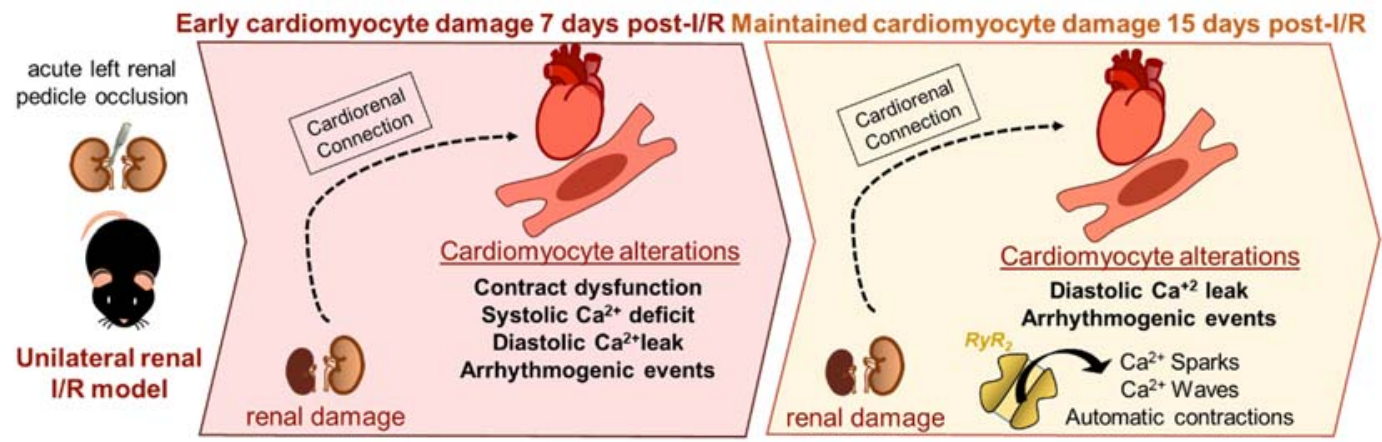

Figure 7. Schematic drawing of the take-home messages.

\section{Materials and Methods}

\subsection{Animal Procedures}

The animal study was conducted following the recommendations of the Spanish Animal Care and Use Committee according to the Guidelines for Ethical Care and Welfare (2013/175) of experimental animals and the directive of the European Union (2010/63/EU) on the protection of animals used for scientific purposes. The General Directorate of Agriculture and the Environment of the Environment Council of Madrid approved the study (PROEX 186.5/20). Male C57BL/6 mice (6-8 weeks of age, 20-25 g) were purchased from Charles River Laboratories International (Brussels, Belgium). Mice were group housed in cages (maximum of five) at the Experimental Animal Center, Hospital Universitario 12 de Octubre. Mice were maintained on a 12-h light/dark artificial cycle, at a constant ambient temperature of $23-25{ }^{\circ} \mathrm{C}$, with ad libitum access to water and a standard diet.

\subsection{Experimental Renal Ischemia/Reperfusion}

Mice underwent sham or I/R surgery using a previously described procedure [10,12,15]. Isoflurane $1.5 \%$ was used to anesthetize the mice. To simulate renal ischemia, the left renal pedicle was exposed after an abdominal incision, and was occluded using a microvascular clamp for $60 \mathrm{~min}$. After this time, the clamp was removed, and the animals were sutured using silk thread. Meloxicam $(0.06 \mathrm{~mL} / \mathrm{kg}$; single dose; s.c.) was used as analgesia after surgery. Mice were randomly divided into three groups: sham and renal ischemia with 7 (7 d I/R) or 15 days (15 d I/R) of reperfusion. These timepoints were selected considering the alterations previously studied by the group that demonstrate relevant cardiac alterations at the 7th and 15th day of renal I/R [10,13-15]. After the first week of reperfusion we observed the increase of inflammatory cytokines, cardiac cell damage and functional cardiac alterations $[10,13,15]$. After the second week, we observed the cardiac hypertrophy and the prevalence of electrical alterations [10,15]. Consequently, animals were euthanized 7 or 15 days following surgery and blood samples, heart and kidneys samples were collected for processing. Samples were maintained at $-80{ }^{\circ} \mathrm{C}$ until analysis.

\subsection{Biochemical Assays}

The Urea Assay Kit (BioAssay Systems, Hayword, CA, USA) was used to measure plasmatic urea and blood urea nitrogen (BUN) levels. The Phosphate Assay Kit (Abcam, Cambridge, UK) was used to measure plasmatic phosphate. Lastly, the FGF-23 Dosing Kit (Immutopics, San Clemente, CA, USA) was used to measure plasmatic FGF-23 levels by ELISA. All assays were used according to the manufacturers' recommendations.

\subsection{Isolation of Adult Ventricular Cardiomyocytes}

Mice were anesthetized with sodium pentobarbital-heparin $(100 \mathrm{mg} / \mathrm{kg}$, i.p.) and the heart was rapidly removed. It was connected to a Langendorff perfusion system through the ascending aorta [19]. A Ca ${ }^{2+}$-free Tyrode's solution was used to retrograde perfuse the hearts. After that, the hearts were digested using a type II collagenase solution with $1 \mathrm{mg} / \mathrm{mL}$ (Worthington, Lakewood, NY, USA), as previously described [36]. Then, hearts 
were removed from the Langendorff apparatus and ventricles were cut into small pieces to disperse the isolated ventricular cardiomyocytes. Cell suspensions were filtered through a 250- $\mu \mathrm{m}$ nylon mesh and then pelleted by centrifugation for $3 \mathrm{~min}$ at $20 \times g$ and suspended in Tyrode's solution. Only rod-shaped, excitable under electrical pacing and $\mathrm{Ca}^{2+}$-tolerant cardiomyocytes with clear cross-striations were selected and used for intracellular $\mathrm{Ca}^{2+}$ imaging studies.

\subsection{Intracellular $\mathrm{Ca}^{2+}$ Imaging}

An intracellular fluorescent calcium dye Fluo-3AM $(5 \mu \mathrm{mol} / \mathrm{L}$; Invitrogen, Carlsbad, CA, USA) was used to load the isolated ventricular cardiomyocytes. They were field stimulated by two electrodes at $2 \mathrm{~Hz}$. Intracellular $\mathrm{Ca}^{2+}$ was imaged by confocal microscopy (Meta Zeiss LSM510, Jena, Germany. Objective $40 \times, 1.2 \mathrm{NA}$ ) at the speed of $1.5 \mathrm{~ms} /$ line (1000 lines per image) for recording $\mathrm{Ca}^{2+}$ transients, $\mathrm{Ca}^{2+}$ sparks and $\mathrm{Ca}^{2+}$ wave images, and at $3 \mathrm{~ms} /$ line $\left(10,000\right.$ lines per image) for caffeine and arrhythmia protocols. All $\mathrm{Ca}^{2+}$ images were corrected for background fluorescence. For $\mathrm{Ca}^{2+}$ transients, the fluorescence value $(\mathrm{F})$ was normalized by baseline fluorescence $\left(\mathrm{F}_{0}\right)$ to obtain $\mathrm{F} / \mathrm{F}_{0}$. The decay time constant of the $\mathrm{Ca}^{2+}$ transients, Tau, was obtained by adjusting the decay trace of the fluorescence to a single exponential. The measurement of the cell shortening was made using the difference of cardiomyocyte length between electrical stimulation and resting period. It was displayed as the percentage cell shortening length. The $\mathrm{Ca}^{2+}$ load of the SR was estimated in intact ventricular myocytes by a quick challenge with $10 \mathrm{mmol} / \mathrm{L}$ caffeine to deplete $\mathrm{Ca}^{2+}$ stores. Caffeine induces $\mathrm{Ca}^{2+}$ release by reducing the threshold for luminal $\mathrm{Ca}^{2+}$ activation of the $\mathrm{RyR}$, causing a total $\mathrm{Ca}^{2+}$ release from intracellular $\mathrm{Ca}^{2+}$ stores [37]. This methodology was previously used by the group to measure the SR $\mathrm{Ca}^{2+}$ load [28,38,39]. To quantify spontaneous $\mathrm{Ca}^{2+}$ sparks, Fluo-3AM-loaded cardiomyocytes were maintained without electrical stimulation and $\mathrm{Ca}^{2+}$ spark regions were determined as the specific sites where the fluorescence signal briefly increased by at least four times the standard deviation of the fluorescence. Abnormal spontaneous $\mathrm{Ca}^{2+}$ release, manifested as $\mathrm{Ca}^{2+}$ waves or automatic $\mathrm{Ca}^{2+}$ transients without electrical stimulation, was quantified by the percentage of occurrence, and globally referred to as spontaneous calcium release (SCR). Three cycles of a $2 \mathrm{~Hz}$ electrical stimulation field were applied to record pro-arrhythmogenic activity. This consisted of seven pulses with a resting period in each cycle. Arrhythmic $\mathrm{Ca}^{2+}$ events were considered to be any spontaneous abnormal release of $\mathrm{Ca}^{2+}$ as waves, missing transients or automatic contractions corresponding to spontaneous $\mathrm{Ca}^{2+}$ transients during the protocol. All $\mathrm{Ca}^{2+}$ images were analyzed using home-made routines with IDL (Research Systems, Boulder, CO, USA) and Image J (National Institutes of Health, Bethesda, MD, USA) softwares.

\subsection{Immunobloting}

Total protein was isolated from hearts by lysing the tissue with an extraction buffer (0.05 M Tris, $0.32 \mathrm{M}$ sucrose, $0.5 \%$ CHAPS, $0.5 \mu \mathrm{M}$ okadaic acid, and the protease inhibitors $0.1 \mathrm{M}$ PMSF, $12 \mu \mathrm{M}$ leupeptin, $0.2 \mu \mathrm{M}$ aprotinin and $0.5 \mathrm{M}$ benzamidine, $\mathrm{pH} 7)$. Protein content was quantified using a BCA kit (Thermo Fisher Scientific, Waltham, MA, USA). Next, $20 \mu \mathrm{g}$ of the extracted proteins was loaded in a 12\% SDS-page gel and was electrophoresed for $180 \mathrm{~min}$ at a constant voltage of $120 \mathrm{~V}$. Next, the proteins resolved on the gel were transferred onto a PVDF membrane using a semi-dry transfer system (Trans-Blot SD, Bio-Rad, Hercules, CA, USA). The membranes were blocked with 5\% skimmed milk in TBST buffer (TBS, $0.1 \%$ Tween 20) for $1 \mathrm{~h}$ and incubated overnight at $4{ }^{\circ} \mathrm{C}$ with primary antibodies. After washing, the membrane was incubated with a corresponding peroxidase-conjugated secondary antibody for $1 \mathrm{~h}$ at room temperature. Finally, the membrane was analyzed using an ECL system (Thermo Fisher Scientific, Waltham, MA, USA). Protein bands were visualized using ImageQuant LAS4000 and band densities were measured using ImageJ software (National Institutes of Health, Bethesda, MD, USA). Primary antibodies used were anti-SERCA $_{2 \mathrm{a}}$ antibodies at 1:2.000 dilution (Abcam, Cambridge, UK) and anti-GAPDH an- 
tibodies at 1:200,000 (Thermo Fisher Scientific, Waltham, MA, USA). Secondary antibodies used were anti-mouse at 1:5000 dilution (Santa Cruz Biotechnology, Dallas, TX, USA).

\subsection{Statistical Analysis}

Data are here stated as mean \pm standard error of the mean (SEM). Statistical significance was accomplished applying an un-paired Student's test, $\chi^{2}$ test or analysis of variance (ANOVA), with a Newman-Keuls multiple comparison test used when appropriate. It was performed with OriginPro 9.0 (OriginLab, Northampton, MA, USA) or GraphPad Prism v6.0 (GraphPad Software Inc., San Diego, CA, USA). Differences with $p$-values $<0.05$ were considered statistically significant.

Author Contributions: G.R.-H. and M.S.C.-R. designed and conceptualized the experiments. C.V.C.J. performed the majority of experiments and analysis of the data, supervised and helped by L.G.-L., J.A.N.-G. and E.R.-S., G.R.-H. and M.S.C.-R. contributed reagents/material and wrote the manuscript. All authors have read and agreed to the published version of the manuscript.

Funding: The authors acknowledge the support from The São Paulo Research Foundation (FAPESP) grants 2018/19204-9, 2018/03089-6, 2015/19107-5, 2019/11077-0 and from projects at the Instituto de Salud Carlos III (PI17/01093, PI17/01193, PI20/00763, CP15/00129, CPII20/00022, FI18/00261, FI21/00212). The study was co-funded by the European Regional Development Fund and SENEFRO Foundation from Spanish Society of Nephrology.

Institutional Review Board Statement: The animal study was conducted following recommendations of the Spanish Animal Care and Use Committee according to the Guidelines for Ethical Care and Welfare (2013/175) of experimental animals and the directive of the European Union (2010/63/EU) on the protection of animals used for scientific purposes. The General Directorate of Agriculture and the Environment of the Environment Council of Madrid approved the study (PROEX 186.5/20).

Informed Consent Statement: Not applicable.

Data Availability Statement: Not applicable.

Acknowledgments: We thank Monserrat Grau Sanz for her excellent assistance with experimental animal facilities of the Instituto de Investigación Hospital 12 de Octubre (imas12), Madrid, Spain. We also thanks to Kenneth McCreath for English editing.

Conflicts of Interest: The authors declare no conflict of interest.

\section{Abbreviations}

\begin{tabular}{|c|c|}
\hline ARF & acute renal failure \\
\hline BUN & blood urea nitrogen \\
\hline BW & body weight \\
\hline $\mathrm{Ca}^{2+}$ & calcium \\
\hline CRS & cardiorenal syndrome \\
\hline EC & excitation-contraction \\
\hline FGF-23 & fibroblast growth factor- 23 \\
\hline HF & heart failure \\
\hline HW & heart weight \\
\hline $\mathrm{I} / \mathrm{R}$ & ischemia and reperfusion \\
\hline IRI & ischemia reperfusion kidney injury \\
\hline LKW & left kidney weight \\
\hline RKW & right kidney weight \\
\hline $\mathrm{RyR}_{2}$ & ryanodine receptor \\
\hline SERCA $_{2 \mathrm{a}}$ & sarcoplasmic/endoplasmic reticulum $\mathrm{Ca}^{2+}$-adenosine triphosphatase $2 \mathrm{a}$ \\
\hline SCR & spontaneous calcium release \\
\hline SR & sarcoplasmic reticulum \\
\hline TL & tibia length \\
\hline
\end{tabular}




\section{References}

1. Gao, Y.; Zeng, Z.; Li, T.; Xu, S.; Wang, X.; Chen, Z.; Lin, C. Polydatin inhibits mitochondrial dysfunction in the renal tubular epithelial cells of a rat model of sepsis-induced acute kidney injury. Anesth. Analg. 2015, 121, 1251-1260. [CrossRef] [PubMed]

2. Benck, U.; Schnuelle, P.; Krüger, B.; Nowak, K.; Riester, T.; Mundt, H.; Lutz, N.; Jung, M.; Birck, R.; Krämer, B.K.; et al. Excellent graft and patient survival after renal transplantation from donors after brain death with acute kidney injury: A case-control study. Int. Urol. Nephrol. 2015, 47, 2039-2046. [CrossRef] [PubMed]

3. Zhu, Y.-B.; Zhang, Y.P.; Zhang, J.; Zhang, Y.B. Evaluation of Vitamin C supplementation on kidney function and vascular reactivity following renal ischemic injury in mice. Kidney Blood Press. Res. 2016, 41, 460-470. [CrossRef] [PubMed]

4. Sawhney, S.; Marks, A.; Fluck, N.; Levin, A.; Prescott, G.; Black, C. Intermediate and Long-term Outcomes of Survivors of Acute Kidney Injury Episodes: A Large Population-Based Cohort Study. Am. J. Kidney Dis. 2017, 69, 18-28. [CrossRef]

5. Ronco, C.; Bellomo, R.; Kellum, J.A. Acute kidney injury. Lancet 2019, 394, 1949-1964. [CrossRef]

6. Doi, K. Kidney-Heart Interactions in Acute Kidney Injury. Nephron 2016, 134, 141-144. [CrossRef]

7. Groeneveld, A.B.J.; Tran, D.D.; van der Meulen, J.; Nauta, J.J.P.; Thijs, L. Acute Renal Failure in the Medical Intensive Care Unit: Predisposing, Complicating Factors and Outcome. Nephron 1991, 59, 602-610. [CrossRef]

8. Ronco, C.; Bellasi, A.; Di Lullo, L. Cardiorenal Syndrome: An Overview. Adv. Chronic Kidney Dis. 2018, 25, 382-390. [CrossRef]

9. Bonventre, J.V.; Yang, L. Cellular pathophysiology of ischemic acute kidney injury. J. Clin. Investig. 2011, 121, 4210-4221. [CrossRef]

10. Trentin-Sonoda, M.; Da Silva, R.C.; Kmit, F.V.; Abrahão, M.V.; Cahli, G.M.; Brasil, G.V.; Muzi-Filho, H.; Silva, P.A.; Tovar-Moll, F.F.; Vieyra, A.; et al. Knockout of toll-like receptors 2 and 4 prevents renal ischemia-reperfusion-induced cardiac hypertrophy in mice. PLoS ONE 2015, 10, e0139350. [CrossRef]

11. Junho, C.V.C.; Panico, K.; Nakama, K.K.; Sonoda, M.T.; Christoffolete, M.A.; Beserra, S.S.; Roman-Campos, D.; Carneiro-Ramos, M.S. Time Course of Gene Expression Profile in Renal Ischemia and Reperfusion Injury in Mice. Transplant. Proc. 2020, 52, 2970-2976. [CrossRef] [PubMed]

12. Neres-Santos, R.S.; Junho, C.V.C.; Panico, K.; Caio-Silva, W.; Pieretti, J.C.; Tamashiro, J.A.; Seabra, A.B.; Ribeiro, C.A.J.; CarneiroRamos, M.S. Mitochondrial Dysfunction in Cardiorenal Syndrome 3: Renocardiac Effect of Vitamin C. Cells 2021, $10,3029$. [CrossRef] [PubMed]

13. Caio-Silva, W.; da Silva Dias, D.; Junho, C.V.C.; Panico, K.; Neres-Santos, R.S.; Pelegrino, M.T.; Pieretti, J.C.; Seabra, A.B.; De Angelis, K.; Carneiro-Ramos, M.S. Characterization of the Oxidative Stress in Renal Ischemia/Reperfusion-Induced Cardiorenal Syndrome Type 3. BioMed Res. Int. 2020, 2020, 1605358. [CrossRef] [PubMed]

14. Cirino-Silva, R.; Kmit, F.V.; Trentin-Sonoda, M.; Nakama, K.K.; Panico, K.; Alvim, J.M.; Dreyer, T.R.; Martinho-Silva, H.; CarneiroRamos, M.S. Renal ischemia/reperfusion-induced cardiac hypertrophy in mice: Cardiac morphological and morphometric characterization. JRSM Cardiovasc. Dis. 2017, 6, 204800401668944. [CrossRef] [PubMed]

15. Alarcon, M.M.L.; Trentin-Sonoda, M.; Panico, K.; Schleier, Y.; Duque, T.; Moreno-Loaiza, O.; de Yurre, A.R.; Ferreira, F.; Caio-Silva, W.; Coury, P.R.; et al. Cardiac arrhythmias after renal I/R depend on IL-1 $\beta$. J. Mol. Cell. Cardiol. 2019, 131, 101-111. [CrossRef]

16. Rangaswami, J.; Bhalla, V.; Blair, J.E.A.; Chang, T.I.; Costa, S.; Lentine, K.L.; Lerma, E.V.; Mezue, K.; Molitch, M.; Mullens, W.; et al. Cardiorenal Syndrome: Classification, Pathophysiology, Diagnosis, and Treatment Strategies: A Scientific Statement From the American Heart Association. Circulation 2019, 139, e840-e878. [CrossRef]

17. Dridi, H.; Kushnir, A.; Zalk, R.; Yuan, Q.; Melville, Z.; Marks, A.R. Intracellular calcium leak in heart failure and atrial fibrillation: A unifying mechanism and therapeutic target. Nat. Rev. Cardiol. 2020, 17, 732-747. [CrossRef]

18. Kansakar, U.; Varzideh, F.; Jankauskas, S.S.; Gambardella, J.; Trimarco, B.; Santulli, G. Advances in the understanding of excitationcontraction coupling: The pulsing quest for drugs against heart failure and arrhythmias. Eur Heart J. Cardiovasc. Pharmacother. 2021, 7, e91-e93. [CrossRef]

19. Ruiz-Hurtado, G.; Li, L.; Fernández-Velasco, M.; Rueda, A.; Lefebvre, F.; Wang, Y.; Mateo, P.; Cassan, C.; Gellen, B.; Benitah, J.P.; et al. Reconciling depressed $\mathrm{Ca}^{2+}$ sparks occurrence with enhanced RyR2 activity in failing mice cardiomyocytes. J. Gen. Physiol. 2015, 146, 295-306. [CrossRef]

20. Val-Blasco, A.; Piedras, M.J.G.M.; Ruiz-Hurtado, G.; Suarez, N.; Prieto, P.; Gonzalez-Ramos, S.; Gómez-Hurtado, N.; Delgado, C.; Pereira, L.; Benito, G.; et al. Role of NOD1 in Heart Failure Progression via Regulation of Ca ${ }^{2+}$ Handling. J. Am. Coll. Cardiol. 2017, 69, 423-433. [CrossRef]

21. Di Fonso, A.; Pietrangelo, L.; D'Onofrio, L.; Michelucci, A.; Boncompagni, S.; Protasi, F. Ageing Causes Ultrastructural Modification to Calcium Release Units and Mitochondria in Cardiomyocytes. Int. J. Mol. Sci. 2021, 22, 8364. [CrossRef]

22. Eckardt, K.U.; Kasiske, B.L. Improving Global Outcomes. Nat. Rev. Nephrol. 2009, 5, 650-657. [CrossRef] [PubMed]

23. Pavez-Giani, M.G.; Sánchez-Aguilera, P.I.; Bomer, N.; Miyamoto, S.; Booij, H.G.; Giraldo, P.; Oberdorf-Maass, S.U.; Nijholt, K.T.; Yurista, S.R.; Milting, H.; et al. ATPase Inhibitory Factor-1 Disrupts Mitochondrial Ca ${ }^{2+}$ Handling and Promotes Pathological Cardiac Hypertrophy through CaMKIII. Int. J. Mol. Sci. 2021, 22, 4427. [CrossRef] [PubMed]

24. Gambardella, J.; Trimarco, B.; Iaccarino, G.; Santulli, G. New Insights in Cardiac Calcium Handling and Excitation-Contraction Coupling. Adv. Exp. Med. Biol. 2018, 1067, 373-385. [CrossRef] [PubMed]

25. Fernández-Morales, J.C.; Xia, Y.; Renzo, T.J.; Zhang, X.H.; Morad, M. Mutation in RyR2-FKBP Binding site alters Ca ${ }^{2+}$ signaling modestly but increases "arrhythmogenesis" in human stem cells derived cardiomyocytes. Cell Calcium. 2022, 101, 102500. [CrossRef] [PubMed] 
26. Kushnir, A.; Santulli, G.; Reiken, S.R.; Coromilas, E.; Godfrey, S.J.; Brunjes, D.L.; Colombo, P.C.; Yuzefpolskaya, M.; Sokol, S.I.; Kitsis, R.N.; et al. Ryanodine Receptor Calcium Leak in Circulating B-Lymphocytes as a Biomarker in Heart Failure. Circulation 2018, 138, 1144-1154. [CrossRef] [PubMed]

27. Wolf, M. Forging Forward with 10 Burning Questions on FGF23 in Kidney Disease. J. Am. Soc. Nephrol. 2010, $21,1427-1435$. [CrossRef]

28. Neyra, J.A.; Moe, O.W.; Hu, M.C. Fibroblast growth factor 23 and acute kidney injury. Pediatr. Nephrol. 2015, 30, 1909-1918. [CrossRef]

29. Leaf, D.E.; Jacob, K.A.; Srivastava, A.; Chen, M.E.; Christov, M.; Jüppner, H.; Sabbisetti, V.S.; Martin, A.; Wolf, M.; Waikar, S.S. Fibroblast Growth Factor 23 Levels Associate with AKI and Death in Critical Illness. J. Am. Soc. Nephrol. 2017, 28, 1877-1885. [CrossRef]

30. Memmos, E.; Papagianni, A. New Insights into the Role of FGF-23 and Klotho in Cardiovascular Disease in Chronic Kidney Disease Patients. Curr. Vasc. Pharmacol. 2020, 19, 55-62. [CrossRef]

31. Navarro-García, J.A.; Delgado, C.; Fernández-Velasco, M.; Val-Blasco, A.; Rodríguez-Sánchez, E.; Aceves-Ripoll, J.; GómezHurtado, N.; Bada-Bosch, T.; Mérida-Herrero, E.; Hernández, E.; et al. Fibroblast growth factor-23 promotes rhythm alterations and contractile dysfunction in adult ventricular cardiomyocytes. Nephrol. Dial. Transplant. 2019, 34, 1864-1875. [CrossRef]

32. Navarro-García, J.A.; Fernández-Velasco, M.; Delgado, C.; Delgado, J.F.; Kuro-o, M.; Ruilope, L.M.; Ruiz-Hurtado, G. PTH, vitamin D, and the FGF-23-klotho axis and heart: Going beyond the confines of nephrology. Eur. J. Clin. Investig. 2018, 48. [CrossRef]

33. Kao, Y.-H.; Chen, Y.-C.; Lin, Y.-K.; Shiu, R.-J.; Chao, T.-F.; Chen, S.-A.; Chen, Y.-J. FGF-23 dysregulates calcium homeostasis and electrophysiological properties in HL-1 atrial cells. Eur. J. Clin. Investig. 2014, 44, 795-801. [CrossRef]

34. Geach, T. FGF-23 associated with incident AF-A link with CKD? Nat. Rev. Cardiol. 2014, 11, 436. [CrossRef]

35. Lindner, M.; Mehel, H.; David, A.; Leroy, C.; Burtin, M.; Friedlander, G.; Terzi, F.; Mika, D.; Fischmeister, R.; Prié, D. Fibroblast growth factor 23 decreases PDE4 expression in heart increasing the risk of cardiac arrhythmia; Klotho opposes these effects. Basic Res. Cardiol. 2020, 115, 51. [CrossRef]

36. Navarro-García, J.A.; Rueda, A.; Romero-García, T.; Aceves-Ripoll, J.; Rodríguez-Sánchez, E.; González-Lafuente, L.; Zaragoza, C.; Fernández-Velasco, M.; Kuro-o, M.; Ruilope, L.M.; et al. Enhanced Klotho availability protects against cardiac dysfunction induced by uraemic cardiomyopathy by regulating $\mathrm{Ca}^{2+}$ handling. Br. J. Pharmacol. 2020, 177, 4701-4719. [CrossRef]

37. Cheek, T.R.; Moreton, R.B.; Berridge, M.J.; Stauderman, K.A.; Murawsky, M.M.; Bootman, M.D. Quantal Ca ${ }^{2+}$ release from caffeine-sensitive stores in adrenal chromaffin cells. J. Biol. Chem. 1993, 268, 27076-27083. [CrossRef]

38. Rodríguez-Sánchez, E.; Navarro-García, J.A.; González-Lafuente, L.; Aceves-Ripoll, J.; Vázquez-Sánchez, S.; Poveda, J.; MercadoGarcía, E.; Corbacho-Alonso, N.; Calvo-Bonacho, E.; Fernández-Velasco, M.; et al. Oxidized Low-Density Lipoprotein Associates with Ventricular Stress in Young Adults and Triggers Intracellular $\mathrm{Ca}^{2+}$ Alterations in Adult Ventricular Cardiomyocytes. Antioxidants 2020, 9, 1213. [CrossRef]

39. González-Lafuente, L.; Navarro-García, J.A.; Rodríguez-Sánchez, E.; Aceves-Ripoll, J.; Poveda, J.; Vázquez-Sánchez, S.; MercadoGarcía, E.; Fernández-Velasco, M.; Kuro-o, M.; Liaño, F.; et al. Interplay between mineral bone disorder and cardiac damage in acute kidney injury: From $\mathrm{Ca}^{2+}$ mishandling and preventive role of Klotho in mice to its potential mortality prediction in human. Transl. Res. 2022, in press. [CrossRef] 